\title{
Microscopic and Macroscopic Studies of the Development of Puccinia hemerocallidis in Resistant and Susceptible Daylily Cultivars
}

\author{
Y. H. Li, M. T. Windham, and R. N. Trigiano, Department of Entomology and Plant Pathology, University of Ten- \\ nessee, Knoxville 37996-4560; D. C. Fare, United States Department of Agriculture-Agricultural Research Service \\ (USDA-ARS), Floral \& Nursery Plants Research Unit, McMinnville, TN 37110; and J. M. Spiers and W. E. Copes, \\ USDA-ARS Small Fruit Research Unit, Poplarville, MS 39470
}

\begin{abstract}
Li, Y. H., Windham, M. T., Trigiano, R. N., Fare, D. C., Spiers, J. M., and Copes, W. E. 2007. Microscopic and macroscopic studies of the development of Puccinia hemerocallidis in resistant and susceptible daylily cultivars. Plant Dis. 91:664-668.

Infection and colonization of eight daylily cultivars, which varied in resistance to daylily rust, by Puccinia hemerocallidis was studied macroscopically and microscopically. After germination of urediniospores, appressoria formed at the tip of germ tubes and the fungus penetrated the host through stomatal openings 2 days after inoculation (DAI). Under the infection sites, intercellular hyphae aggregated and formed uredia, which released urediniospores 8 DAI. Resistant cultivars, characterized by the development of rapid death of host cells, were separated into three qualitative categories based on absence and presence of necrotic lesions without or with sporulation. In highly resistant cvs. Prairie Blue Eyes and Bertie Ferris, no macroscopic disease symptoms were observed on leaf surfaces although a few collapsed cells were detected microscopically. Both resistant and moderately resistant reactions were characterized by necrotic lesions with many collapsed cells under infection sites. The difference between these two reactions was that uredia and urediniospores were observed in the moderately resistant cv. Chicago Apache, but not in resistant cvs. Buttered Popcorn and Stella De Oro. Susceptible cultivars, characterized by the absence of a hypersensitive response, were separated into two qualitative categories based on restriction of intercellular hyphal growth that delayed development of uredia and formation of urediniospores. Compared to the susceptible cv. Pardon Me, moderately susceptible cvs. Mary Todd and Chorus Line had a delayed latent period and reduced amount of sporulation. The results indicate that hypersensitive cell death is one of the resistance responses to daylily rust. Necrotic lesions on leaf surfaces are associated with the number of collapsed host cells. Delayed latent period and reduced sporulation that resulted from restriction of intercellular hyphal growth could represent another type of resistance response in the daylily-rust pathosystem.
\end{abstract}

Daylilies (Hemerocallis spp.) are popular ornamental plants because of their long blooming period, various flower colors, and relative freedom from pests and diseases. Daylily rust, caused by Puccinia hemerocallidis Thüm., has threatened daylily production in the United States $(7,29)$. Use of genetic resistance is a cost-effective and environmentally sound strategy in plant disease managements. Although variation of susceptibility to daylily rust in commercial daylily cultivars has been reported in greenhouse experiments (22), the effects of host resistance on the fungal

Corresponding author: M. T. Windham

E-mail: mwindham@utk.edu

Accepted for publication 14 December 2006.

doi:10.1094/PDIS-91-6-0664

This article is in the public domain and not copyrightable. It may be freely reprinted with customary crediting of the source. The American Phytopathological Society, 2007. infection and development are unclear. The ability of a host to impede fungal pathogen growth and development reflects host resistance levels (24). Two types of resistance were defined according to fungal reproduction. Complete resistance represents no sporulation on hosts. Incomplete resistance or partial resistance refers to the resistance reducing the amount of sporulation (24). Understanding mechanisms of resistance in host plants is essential in order to evaluate resistance and determine breeding strategies. The objectives of this study were to describe the infection process of $P$. hemerocallidis, compare macroscopic and microscopic fungal development on daylily cultivars differing in levels of resistance, and investigate resistance mechanisms used by resistant cultivars.

\section{MATERIALS AND METHODS}

Cultivars. Eight daylily cultivars, Buttered Popcorn, Mary Todd, Chorus Line, Chicago Apache, Prairie Blue Eyes, Stella De Oro, Bertie Ferris, and Pardon Me, with different levels of resistance to $P$. hemerocallidis (22) were used in the experiments. Divisions with three fans of daylily cultivars were obtained from Oakes Daylilies (Corryton, TN) and planted in 11.3-liter (no. 3) nursery containers filled with Sunshine Mix no. 1 composed of Canadian sphagnum peat moss, perlite, gypsum, dolomitic lime, and a wetting agent (Sun Gro Horticulture, Bellevue, WA) in a greenhouse. As plants grew, older leaves were removed once a month to stimulate new leaf production. Leaf segments $(5 \mathrm{~cm}$ long) were excised from the middle part of new leaves, rinsed in running water, and inoculated with the pathogen.

Inoculum and inoculation. A singlepustule isolate of $P$. hemerocallidis was maintained on leaf segments of daylily cv. Pardon Me in petri dishes with moistened filter papers in a laboratory under continuous light. Fresh leaf segments were inoculated and replaced older ones at 8-day intervals. A preliminary inoculation study had revealed that abaxial leaf surfaces had more stoma and resulted in more infection sites than did adaxial leaf surfaces. Leaf segments were placed at the bottom of a settling tower with abaxial surface up, sprayed lightly with distilled water, and inoculated with the pathogen using the method described by Li et al. (13). The inoculum density on leaf segments was adjusted to approximately 200 urediniospores $/ \mathrm{cm}^{2}$ of leaf area by repeated blasts of air. Urediniospores per unit area were calculated according to the count from a glass slide placed beside the leaf segments in the settling tower. Inoculated leaf segments were placed on moistened paper towels with abaxial surface up in a plastic box and incubated in the dark at $20^{\circ} \mathrm{C}$ because increasing light density could decrease the percentage of urediniospore germination of $P$. hemerocallidis (21). After $24 \mathrm{~h}$ of incubation in the dark, leaf segments were moved into 9-cm-diameter petri dishes, with two layers of moistened filter paper and incubated in a temperaturecontrolled laboratory at $20 \pm 2^{\circ} \mathrm{C}$ with continuous light. Light was provided by four $40 \mathrm{~W}$ residential fluorescent bulbs 
from $45 \mathrm{~cm}$ above leaf segments. Temperature was monitored using a thermometer sensor on the bench where the leaf segments were incubated.

Scanning electron microscopy. Inoculated leaf segments $(0.5$ by $0.5 \mathrm{~cm})$ were sampled at 1-day intervals up to 10 days after inoculation (DAI) and directly mounted onto aluminum stubs without fixation. Leaf segments were examined using the Hitachi S-4300 SE/N scanning electron microscope (Hitachi High Technology America, Pleasanton, CA) at 10 to $20 \mathrm{kv}$ in the variable pressure mode. Digital images were acquired using the image processing system in the instrument.

Light microscopy. Leaf samples $(0.2$ by $0.5 \mathrm{~cm}$ ) were cut from inoculated leaf segments at 2-day intervals up to $10 \mathrm{DAI}$ and fixed in $50 \%$ FAA solution $(5 \mathrm{ml}$ of $37 \%$ formaldehyde, $5 \mathrm{ml}$ of glacial acetic acid, $50 \mathrm{ml}$ of $95 \%$ ethanol, and $40 \mathrm{ml}$ of water). After a minimum 24-h fixation period, leaf samples were dehydrated using a graded series of isopropyl alcohol for 30 min and infiltrated with paraffin (Paraplast Plus Tissue Embedding Medium, Oxford Labware, St Louis, MO) in a $60^{\circ} \mathrm{C}$ oven overnight. Samples were embedded in paraffin and $10-\mu \mathrm{m}$ sections were cut using a rotary microtome (Reichert-Jung 820-II HistoCut, Nussloch, West-Germany). Sections were mounted on slides, deparaffined using Microclear (Micron Environmental Industries, Fairfax, VA), and stained with a modified triple stain that included safranin O, crystal violet, and fast green (9). Stained sections were examined under a light microscope to monitor infection structure formation and hyphal growth. The number of collapsed host cells per infection site was determined using the observation of 44 to 98 cross sections with infection sites for each cultivar at 10 DAI. A cell was considered to be collapsed when its outline was visibly distorted and the cell walls or cytoplasm were stained dark red, which indicated death of the cytoplasm.

Symptom development. Development of the macroscopic symptoms was observed daily from the inoculated leaf seg- ments in order to record incubation period and latent period. Incubation period was defined as the time at which macroscopic symptoms were first observed, and latent period was defined as the time at which urediniospores were released from uredia. In order to assess urediniospore production at 10 DAI, each inoculated leaf segment was transferred into $25-\mathrm{ml}$ screwtop tubes containing $8 \mathrm{ml}$ of $0.1 \%$ Tween 20 distilled water solution and agitated using a vortex mixer for $1 \mathrm{~min}$. After removing leaf segments, tubes were centrifuged for $10 \mathrm{~min}$ at $1,000 \times \mathrm{g}$. After discarding the supernatant, pellets in the tubes were resuspended using $0.5 \mathrm{ml}$ of distilled water. Urediniospores in the suspensions were counted using a hemacytometer and a compound microscope. The number of urediniospores per square centimeter of leaf segment was calculated by dividing the number of urediniospores on a leaf segment by the area of the segment. Data of urediniospores per square centimeter of leaf area were transformed using the square root of counts plus one in order to minimize the effects of zero values on analyses of variance (18).

Statistical analysis. Statistical analyses were accomplished using PROC GLM of SAS software (version 9.1; SAS Institute Inc., Cary, NC). The effects of the cultivars on incubation period, latent period, and sporulation were analyzed using a randomized complete block design with subsamplings. Each run of inoculation was considered as a block and three leaf segments of each cultivar in a block were considered as subsamples. For determining the effects of the cultivars on the collapsed cells per infection site, each slide was considered as a block and cross sections in a slide were considered as subsamples. There were four to six blocks in each experiment. When analyses of variance showed that the variability for variables tested among blocks were not significantly different $(P<0.0001)$, data from the blocks were combined. Means were compared using the least significant difference at $P=0.05$.

\section{RESULTS}

Resistance reaction types. According to lesion types and sporulation rates on leaf segments at $10 \mathrm{DAI}$, daylily cultivars were grouped into five categories of susceptibility to $P$. hemerocallidis (Table 1). The susceptible cv. Pardon Me supported abundant spore production from bright yellow uredia (Fig. 1A). On moderately susceptible cvs. Mary Todd and Chorus Line, uredia and urediniospores were formed in brown spots (Fig. 1B). Moderately resistant cv. Chicago Apache exhibited necrotic lesions with few urediniospores released (Fig. 1C). Resistant cvs. Buttered Popcorn and Stella De Oro exhibited necrotic lesions without sporulation (Fig 1D). Cvs. Bertie Ferris and Prairie Blue Eyes were placed in the highly resistant category, with either tiny light specks or no visible symptoms at penetration sites that were surrounded by green area when leaf tissues discolored (Fig. 1E).

Infection process. In the susceptible cv. Pardon Me, germinating urediniospores produced germ tubes on the leaf surface within $24 \mathrm{~h}$. Each urediniospore formed one germ tube (Fig. 2A). Germ tubes stopped elongating at stomata, formed oblong appressoria that took the shape of the stomata, and often had a collapsed appearance (Fig. 2B and C). The infection peg, which originated from the appressorium, penetrated through the stomal opening and formed a spherical substomatal vesicle in the substomatal space from which intercellular hyphae were differentiated (Fig. 3A). Bullet-shaped haustorial mother cells formed at the tip of intercellular hyphae contacting host cells within 2 DAI (Fig. 3A). After penetrating into host cells, the fungus formed haustoria that stained with less density than host cell nuclei (Fig. 3B). Infection hyphae aggregated and formed uredial primordia in the substomatal space under infection sites at 6 DAI (Fig. 3C). Uredia erupted on the abaxial leaf surfaces and released urediniospores about $8 \mathrm{DAI}$ (Figs. 2D and 3D).

Histological observation. By 2 DAI, protoplasts had shrunken away from cell walls in the tissues under infection sites of

Table 1. Resistance category, lesion types, collapsed cell numbers, incubation period, latent period, and sporulation for eight daylily cultivars inoculated with the rust fungus Puccinia hemerocallidis ${ }^{\mathrm{w}}$

\begin{tabular}{lclcccc}
\hline Cultivar & $\begin{array}{c}\text { Resistance } \\
\text { category }^{\mathbf{x}}\end{array}$ & \multicolumn{1}{c}{ Lesion type } & $\begin{array}{c}\text { Collapsed cell/infection } \\
\text { site (10 DAI) }\end{array}$ & $\begin{array}{c}\text { Incubation } \\
\text { period (day) }\end{array}$ & $\begin{array}{c}\text { Latent } \\
\text { period (day) }\end{array}$ & $\begin{array}{c}\text { Sporulation (urediospore/cm } \text { of leaf }^{\mathbf{y}} \\
\text { area 10 DAI) }^{\mathbf{z}}\end{array}$ \\
\hline Pardon Me & S & Bright yellow lesion & $0.3 \mathrm{f}$ & $4.8 \mathrm{c}$ & $7.2 \mathrm{~d}$ & $36,008 \mathrm{a}$ \\
Mary Todd & MS & Brown spot & $1.1 \mathrm{e}$ & $4.2 \mathrm{~d}$ & $8.0 \mathrm{c}$ & $12,754 \mathrm{~b}$ \\
Chorus Line & MS & Brown spot & $3.2 \mathrm{c}$ & $5.6 \mathrm{~b}$ & $8.8 \mathrm{~b}$ & $1,126 \mathrm{c}$ \\
Chicago Apache & MR & Necrotic lesion & $12.2 \mathrm{a}$ & $3.8 \mathrm{e}$ & $9.6 \mathrm{a}$ & $695 \mathrm{~cd}$ \\
Buttered Popcorn & R & Necrotic lesion & $7.1 \mathrm{~b}$ & $3.8 \mathrm{e}$ & $\ldots$ & $0 \mathrm{~d}$ \\
Stella De Oro & R & Necrotic lesion & $3.3 \mathrm{c}$ & $6.4 \mathrm{a}$ & $\ldots$ & $0 \mathrm{~d}$ \\
Bertie Ferris & HR & No visible symptom & $1.8 \mathrm{de}$ & $\ldots$ & $\ldots$ & $0 \mathrm{~d}$ \\
Prairie Blue Eyes & HR & No visible symptom & $2.1 \mathrm{~d}$ & $\ldots$ & $\ldots$ & $0 \mathrm{~d}$ \\
\hline
\end{tabular}

\footnotetext{
${ }^{\text {w}}$ Means followed by the same letter in a column for each variable are not significantly different from each other at the $P=0.05$ level using the least signifi-

cant difference. ... indicates that data were not available because no symptom or pustules were detected.

${ }^{x}$ S: susceptible; MS: moderately susceptible; MR: moderately resistance; R: resistant; HR: highly resistant.

y DAI: days after inoculation.

${ }^{\mathrm{z}}$ Data were analyzed using the square root transformation of the counts of urediniospores per square centimeter of leaf area plus one.
} 
all cultivars except the susceptible cv. Pardon Me (Fig. 3E). Although collapsed host cells had been observed in all cultivars tested (Fig. 3F), the number of collapsed cells per infection site were significantly different $(P<0.0001)$ among cultivars at 10 DAI (Table 1). Moderately resistant cv.
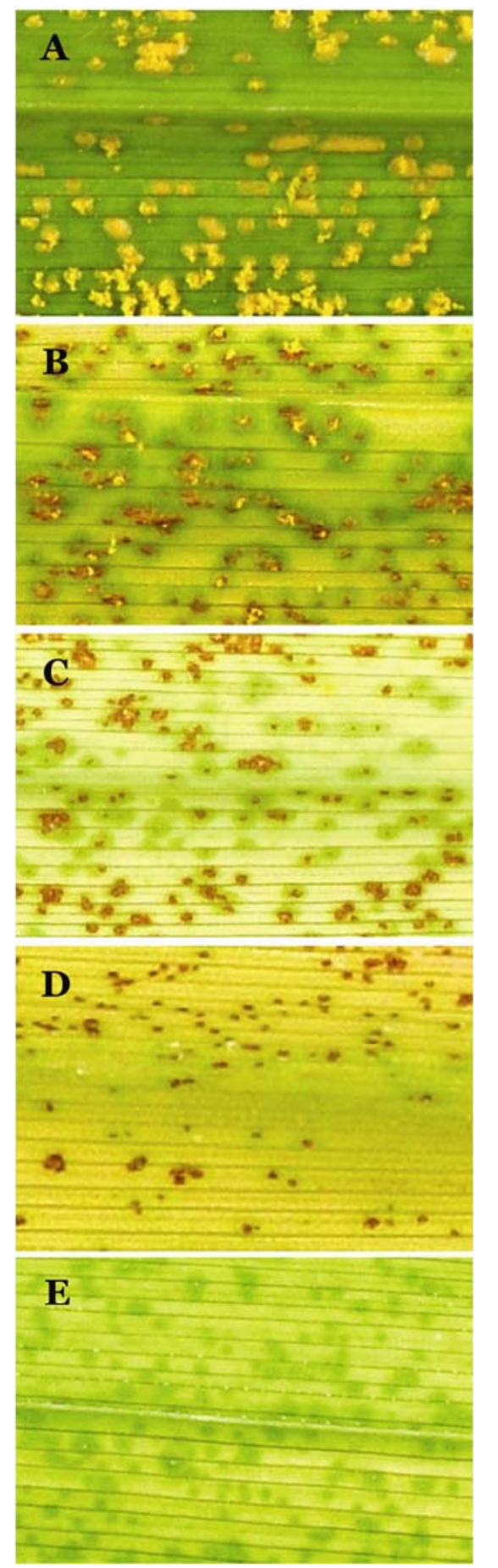

Fig. 1. Symptoms of daylily rust on detached leaf segments of daylily cultivars grouped in five resistance categories at 10 days after inoculation. A, Urediniospores and uredia on susceptible cultivar. B, Urediniospores and uredia on moderately susceptible cultivars. C, Urediniospore release on necrotic lesions on moderately resistant cultivars. D, Necrotic lesions on resistant cultivars. E, Tiny specks or no visible symptom on highly resistant cultivars.
Chicago Apache had the largest proportion of collapsed cells, followed by cvs. Buttered Popcorn, Stella De Oro, Chorus Line, Prairie Blue Eyes, Bertie Ferris, and Mary Todd, whereas collapsed cells rarely were detected in the susceptible cv. Pardon Me (Table 1). Uredia and urediniospores were formed in cvs. Pardon Me, Mary Todd, Chorus Line, and Chicago Apache, but not in cvs. Buttered Popcorn, Stella De Oro, Bertie Ferris, and Prairie Blue Eyes (Table 1).

Symptom development and sporulation. The development of rust symptoms on infected leaf segments was monitored at 1-day intervals over a period of $10 \mathrm{DAI}$. Because macroscopic symptoms were not observed on cvs. Bertie Ferris and Prairie Blue Eyes, statistical analyses of incubation period were conducted for the other six cultivars tested. Incubation period was significantly different $(P<0.0001)$ among daylily cultivars tested. Brown spots that were observed on cvs. Buttered Popcorn and Chicago Apache at 4 DAI developed into necrotic lesions at 5 DAI. On cvs. Mary Todd and Chorus Line, brown spots were observed at 4 to $5 \mathrm{DAI}$ and uredia formed at 6 DAI. The mean incubation period was longest in cv. Stella De Oro at 6.4 DAI (Table 1).

The absence of pustules on cvs. Prairie Blue Eyes, Bertie Ferris, Buttered Popcorn, and Stella De Oro prevented quantitative measurements of the fungal asexual reproduction on these cultivars. Therefore, latent period could be compared only among cvs. Pardon Me, Mary Todd, Chicago Apache, and Chorus Lines. Significant differences $(P<0.0001)$ in latent period were observed among the four cultivars. Compared with susceptible cv. Pardon $\mathrm{Me}$, latent period was significantly delayed in cvs. Mary Todd, Chorus Line,
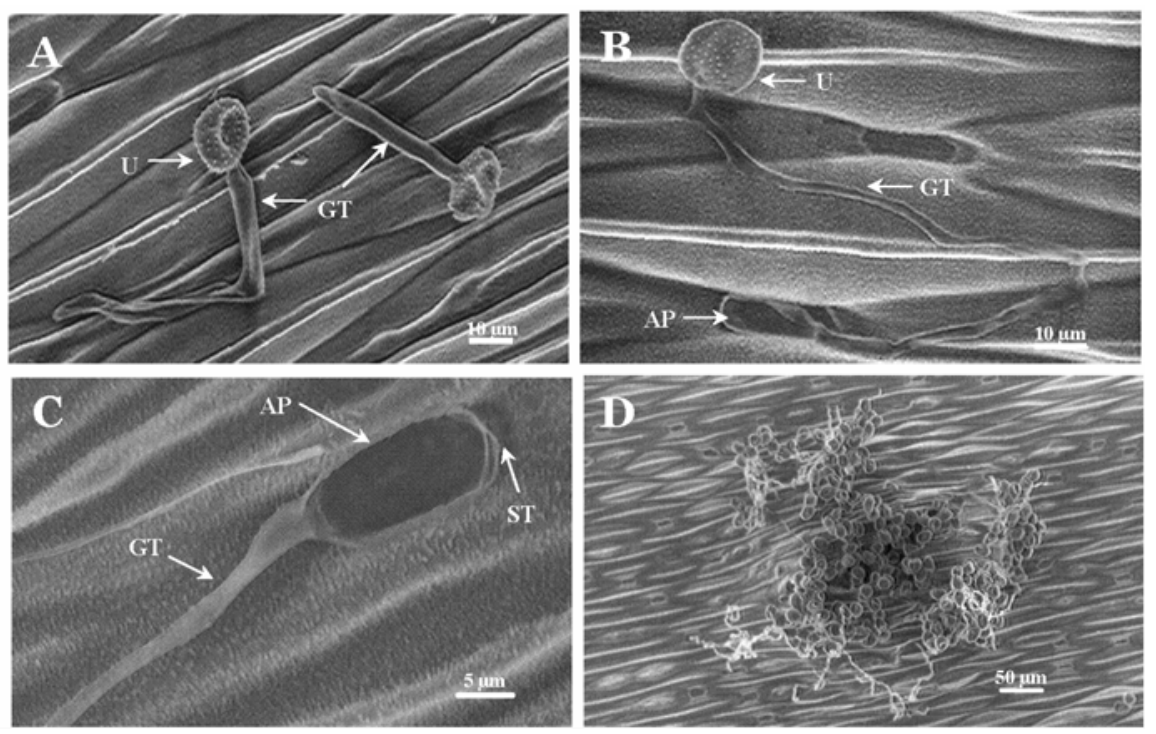

Fig. 2. Scanning electron micrographs of the infection process of Puccinia hemerocallidis on susceptible daylily cv. Pardon Me. A, Differentiation of germ tubes (GT) from urediniospores (U) at 1 day after inoculation (DAI). B, Formation of an appressorium (AP) at the end of germ tube over a stoma (ST) 1 DAI. C, Closeup of an appressorium over a stoma. D, Urediniospores from a uredium at 9 DAI. 
under the infection sites in the daylily cultivars tested, but the number of collapsed host cells varied. Macroscopic manifestation of hypersensitive reaction (HR) to daylily rust on leaf surfaces was associated with the number of collapsed cells under the infection sites. McLean (19) reported that there were no macroscopic symptoms on immune soybean (Glycine max (L.) Merrill) cultivars to Phakopsora pachyrhizi Sydow, and HR was limited to a few cells at the microscopic level. In the present study, highly resistant cultivars had a few collapsed cells under infection sites, but did not show macroscopic necrotic lesions on the leaf surface. Macroscopic necrotic lesions on resistant and moderately resistant cultivars might be due to a greater number of col- lapsed cells under the infection sites than the highly resistant cultivars.

HR is used as evidence of incompatible plant-pathogen interactions (27). Melampsora rust on willow can reproduce only in compatible interactions, not in incompatible interactions (8). For diploid wheat rust caused by Puccinia triticina Eriks., however, small pustules were observed on the hypersensitive necrotic flecks (1). In the present study, extensive intercellular hyphae growth in the plant tissues under infection sites and urediniospore production were observed in necrotic lesions on the moderately resistant cultivar. Collapsed cells also were observed microscopically in the infected tissues of moderately susceptible daylily cultivars, although necrotic lesions were not detected macroscopically on leaf segments. Rust fungi could obtain sufficient nutrition from host cells before they collapsed to maintain limited growth and to support some sporulation (12), and $\mathrm{HR}$ is not always associated with an incompatible interaction. In some highly resistant cultivars, little or no host cell death occurred during the first 5 days of the inoculation (3). According to the study of $P$. graminis tritici Eriks. \& E. Henn. in wheat cultivars, hypersensitive cell collapse was proposed as a consequence, not the cause, of resistance to infection $(4,23)$. In the present study, no positive relation between percent collapsed cells and resistance levels supported this concept.

Latent period and sporulation were reported as major components for evaluation of partial resistance to fungal diseases
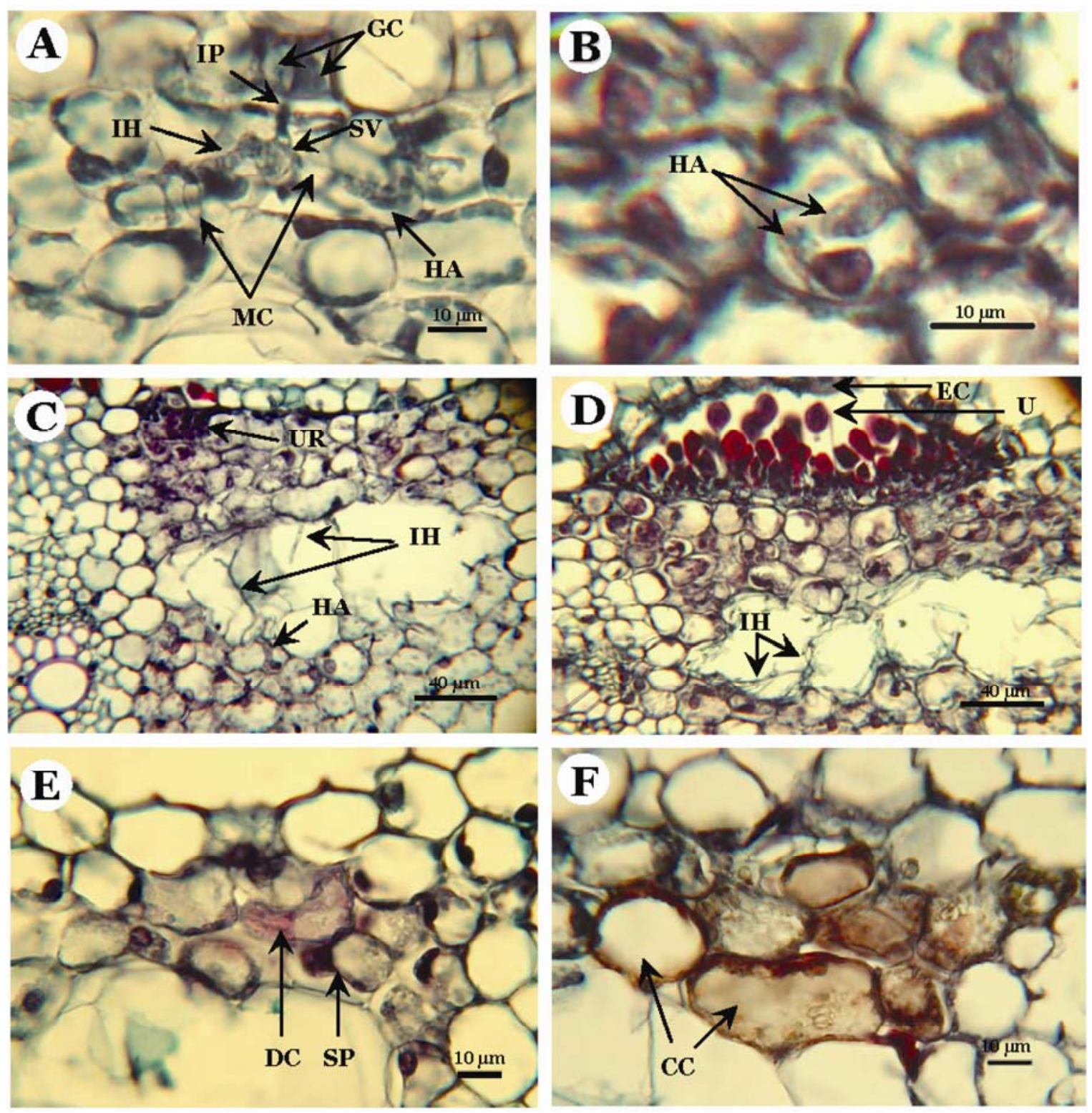

Fig. 3. Light micrographs of infection process of Puccinia hemerocallidis. A, Infection peg (IP) that grew between the guard cells (GC), intercellular hyphae (IH) differentiated from a spherical substomatal vesicle (SV) in the substomatal space, haustorial mother cells (MC) at the tip of IH, and a haustorium (HA) in a mesophyll cell of cv. Pardon Me at 2 days after inoculation (DAI). B, HA in a mesophyll cell of cv. Pardon Me at 6 DAI. C, Formation of a uredium (UR) in the substomatal space under a stoma of cv. Pardon Me at 6 DAI. D, Mature urediniospores (U) under epidemical cells (EC) of cv. Pardon Me at 8 DAI. E, Shrunken protoplast (SP) and dead cells (DC) in cv. Prairie Blue Eyes at 2 DAI. F, Collapsed mesophyll cells (CC) in cv. Chicago Apache at 4 DAI. 
$(2,5,17,24,28)$. The mean latent period of crown rust for the oat lines with partial resistance was 4.7 days longer than the latent period for the susceptible cv. Starter (5). Martínez et al. (17) reported that the wheat lines with partial resistance genes $L r 34$ and $L r 46$ prolonged latent period of leaf rust 1.2 and 0.6 days compared with susceptible cv. Lalbahadur. For daylily rust, Mueller et al. (22) reported that sporulation on susceptible cv. Pardon $\mathrm{Me}$ started within 8 to 12 DAI, whereas sporulation started at 18 DAI on moderately susceptible cvs. Ice Carnival, Mini Pearl, and Seeing Red. In the present study, latent period on the moderately resistant $\mathrm{cv}$. Chicago Apache was 2.4 days longer than the latent period on susceptible cv. Pardon $\mathrm{Me}$ (7.2 days). Although there were differences in the time of prolonged latent period resulting from different pathosystems and experiment conditions, delayed latent period was an important component of partial resistance. Mueller et al. (22) grouped cvs. Chorus Line, Mary Todd, and Pardon Me into the susceptible reaction. In our study, Chorus Line and Mary Todd were grouped into the moderately susceptible categories according to a significantly smaller amount of sporulation than susceptible cv. Pardon Me. Delayed latent period and reduced urediniospore production for moderately resistant and moderately susceptible cultivars indicate that cvs. Chicago Apache, Chorus Line, and Mary Todd may possess quantitative or partial resistance to daylily rust. Infection types and resistance components proposed in the present study could be used to evaluate daylily rust resistance on leaf segments in a laboratory.

Rusts are obligate parasites and highly host specific. In some rust species, specialized forms and physiologic races are defined according to the specificity to host species and cultivars (14). Host specificity or genetic diversity has not been reported in $P$. hemerocallidis. In the present study, resistance categories were grouped according to host reactions to single-pustule isolate inoculation. Further work is needed to determine the stability of resistance levels to different populations and investigate host specificity of $P$. hemerocallidis.

\section{ACKNOWLEDGMENTS}

This study was supported by funding from USDA-ARS (58-6404-2-0057). We thank X. H.
Tang in the Department of Materials Science and Engineering at the University of Tennessee for help with scanning electron microscopy.

\section{LITERATURE CITED}

1. Anker, C. C., and Niks, R. E. 2001. Prehaustorial resistance to the wheat leaf rust fungus, Puccinia triticina, in Triticum monococcum (s.s.). Euphytica 117:209-215

2. Broers, L. H. M. 1997. Components of quantitative resistance to yellow rust in ten spring bread wheat cultivars and their relations with field assessments. Euphytica 96:215-223.

3. Brown, J. F. 1998. Reflections of a traditional plant pathologist. Aust. Plant Pathol. 27:1-14.

4. Brown, J. F., Shipton, W. A., and White, N. H. 1966. The relationship between hypersensitive tissue and resistance in wheat seedlings infected with Puccinia graminis tritici. Ann. Appl. Biol. 58:279-290.

5. Díaz-Lago, J. E., Stuthman, D. D., and Leonard, K. J. 2003. Evaluation of components of partial resistance to oat crown rust using digital image analysis. Plant Dis. 87:667-674.

6. Heath, M. C. 1997. Signaling between pathogenic rust fungi and resistant or susceptible host plants. Ann. Bot. 80:713-720.

7. Hermández, J. R., Palm, M. E., and Castlebury, L. A. 2002. Puccinia hemerocallidis, cause of daylily rust, a newly introduced disease in the Americans. Plant Dis. 86:1194-1198.

8. Hurtado, S. P., and Ramstedt, M. 2000. Compatible and incompatible reactions of Melampsora rust on willow leaves. Scand. J. For. Res. 15:405-409.

9. Johansen, D. A. 1940. Plant Microtechnique. McGraw-Hill Co., New York.

10. Kemen, E., Hahn, M., Mendgen, K., and Struck, C. 2005. Different resistance mechanisms of Medicago truncatula ecotypes against the rust fungus Uromyces striatus. Phytopathology 95:153-157.

11. Laurans, F., and Pilate, G. 1999. Histological aspects of a hypersensitive response in poplar to Melampsora larici-populina. Phytopathology 89:233-238.

12. Leonard, K. J., and Szabo, L. J. 2005. Pathogen profile: Stem rust of small grains and grasses caused by Puccinia graminis. Mol. Plant Pathol. 6:99-111.

13. Li, Y. H., Windham, M. T., Trigiano, R. N., Fare, D. C., Spiers, J. M., and Copes, W. E. 2005. Spore germination, infection structure formation, and colony development of Erysiphe pulchra on dogwood leaves and glass slides. Plant Dis. 89:1301-1304.

14. Littlefield, L. J. 2004. Smut and rust diseases. Pages 151-163 in: Plant Pathology: Concepts and Laboratory Exercises. Eds. Trigiano, R. N., Windham, M. T., and Windham, A. S. CRC Press LLC, Boca Raton, FL.

15. Liu, J. Q., and Harder, D. E. 1996. Components of resistance in barley to stem rust: preand post-penetration development in seedling and adult plant leaves. Can. J. Bot. 74:13051312.

16. Mares. D. J. 1979. Microscopic study of the development of yellow rust (Puccinia stri- iformis) in a wheat cultivar showing adult plant resistance. Physiol. Plant Pathol. 15:289-296.

17. Martínez, F., Niks, R. E., Singh, R. P., and Rubiales, D. 2001. Characterization of Lr46, a gene conferring partial resistance to wheat leaf rust. Hereditas 135:111-114.

18. May, R. A., and Trigiano, R. N. 1991. Somatic embryogenesis and plant regeneration from leaves of Dendranthema grandiflora. J. Am. Soc. Hortic. Sci. 116:366-371.

19. McLean, R. J. 1979. Histological studies of resistance to soybean rust, Phakopsora pachyrhizi Syd. Aust. J. Agric. Res. 30:77-84.

20. Mellersh, D. G., and Heath, M. C. 2004. Cellular expression of resistance to fungal plant pathogens. Pages 31-55 in: Fungal Disease Resistance in Plants: Biochemistry, Molecular Biology, and Genetic Engineering. Z. K. Punja, ed. Food Products Press, Binghamton, NY.

21. Mueller, D. S., and Buck, J. W. 2003. Effects of light, temperature, and leaf wetness duration on daylily rust. Plant Dis. 87:442-445.

22. Mueller, D. S., Willliams-Woodward, J. L., and Buck, J. W. 2003. Resistance of daylily cultivars to the daylily rust pathogen, Puccinia hemerocallidis. HortScience 38:1137-1140.

23. Ogle, H. J., and Brown, J. F. 1971. Quantitative studies of post-penetration phase of infection by Puccinia graminis tritici. Ann. Appl. Biol. 67:309-319.

24. Parlevliet, J. E. 1979. Components of resistance that reduce the rate of epidemic development. Annu. Rev. Phytopathol. 17:203222.

25. Silva, M. C., Nicole, M., Guerra-Guimarães L., and Rodrigues, C. J., Jr. 2002. Hypersensitive cell death and post-haustorial defence responses arrest the orange rust (Hemileia vastatrix) growth in resistant coffee leaves. Physiol. Mol. Plant Pathol. 60:169-183.

26. Soto-Estrada, A., Förster, H., DeMason, D. A., and Adaskaveg, J. E. 2005. Initial infection and colonization of leaves and stems of cling peach by Tranzschelia discolor. Phytopathology 95:942-950.

27. Stuible, H. P., and Kombrink, E. 2004. The hypersensitive response and its role in disease resistance. Pages 57-92 in: Fungal Disease Resistance in Plants: Biochemistry, Molecular Biology, and Genetic Engineering. Z. K Punja, ed. Food Products Press, Binghamton, NY.

28. Viljanen-Rollinson, S. L. H., Gaunt, R. E., Frampton, C. M. A., Falloon, R. E., and McNeil, D. L. 1998. Components of quantitative resistance to powdery mildew (Erysiphe pisi) in pea (Pisum sativum). Plant Pathol. 47:137-147.

29. Williams-Woodward, J. L., Hennen, J. F., Pardar, K. W., and Fowler, J. M. 2001. First report of daylily rust in the United States. Plant Dis. 85:1121.

30. Xavier, A. A., Alfenas, A. C., Matsuoka, K., and Hodges, C. S. 2001. Infection of resistant and susceptible Eucalyptus grandis genotypes by urediniospores of Puccinia psidii. Aust. Plant Pathol. 30:277-281. 